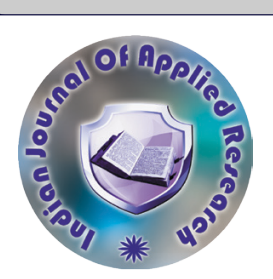

\title{
DEVELOPMENT OF KAP TOOL AND ITS APPLICATION IN ASSESSMENT OF YOUNG FEMALES WITH PCOS.
}

\section{Mrs. Shubhi Agarwal*}

\section{Dr.Usha Devi C}

M.Sc.NET, PhD scholar, Dept. of Food and Nutrition and Research Centre, Smt.V.H.D.Central institute of Home science. Assistant professor, Mount Carmel College, Autonomous, Bengaluru University, Bengaluru.*Corresponding Author $\mathrm{PhD}$, Associate professor, Head of the Dept. of Food and Nutrition and Research Centre, Smt.V.H.D.Central institute of Home science, Bengaluru University, Bengaluru

ABSTRACT BACKGROUND: Polycystic ovary syndrome (PCOS) is the most common endocrine disorder amongst women of reproductive age associated with various clinical and psychological manifestations. Promoting awareness and lifestyle modifications is essential to empower the female PCOS population to take health care decisions for the treatment and management OBJECTIVE: Assessment of knowledge, attitude and practice(KAP) among PCOS population is significant in behavioral and lifestyle modification. Thus, the present study was undertaken to develop a KAP tool. METHODS:An observational, non-controlled study was conducted using random sampling in the age range of 15-25 years. A total of 600 subjects were screened with the help of a standardized screening questionnaire and the presence of PCOS was confirmed using the Rotterdam criteria (2003).A KAP tool validated by an expert panel was given to the subjects confirmed for PCOS to assess knowledge, attitude and practices. The validity was assessed using exploratory factor analysis. The Spearman-Brown correlation coefficients helped to assess reliability for knowledge, attitude and practice domains, which were found to be 0.83 , 0.63 and 0.47 respectively. RESULTS: Significant knowledge was found among confirmed PCOS subjects, but had low attitudes and their practices did not commensurate with their knowledge about PCOS and Nutrition. CONCLUSION: The present research contributes to the understanding of a growing PCOS epidemic in urban India and document the need to screen knowledge, attitude and practice, to develop supportive interventions addressing quality of life issues to reduce the distress among women with PCOS.

KEYWORDS : PCOS; Rotterdam Criteria; glucose tolerance; insulin resistance; KAP; lifestyle modification; development; validation; reliability

\section{INTRODUCTION}

Polycystic ovary syndrome (PCOS) is one of the commonest endocrine disorders seen in young women characterized by three classic symptoms: Irregular menstrual periods ,excessive hair growth and or Polycystic ovaries.[1]

In a survey, it was found to be $9.13 \%$ prevalent among south Indian adolescent girls. [2] World Health Organization (WHO) indicated that PCOS affected 116 million (3.4\%) of women worldwide.[3]

Women with PCOS are also at an increased risk of psychological implications. Lifestyle management is currently advised as the first line management strategy for PCOS.Therefore, assessment of knowledge, attitude and practice is significant in behavioral and lifestyle modification.

\section{OBJECTIVES}

The study aimed at assessing the knowledge, attitude and practices among subjects confirmed for PCOS.

\section{MATERIALAND METHODS}

\section{Sample size and Selection of subjects:}

Random sampling technique was used to select subjects .Screening questionnaire was distributed to 600 subjects. Responses were received from 521 subjects. Based on the inclusion criteria, 56 subjects were considered for the study. Average age of the selected subjects was 21.5 years.

\section{INCLUSION CRITERIA:}

Females aged between $15-25$ years of age.

- Confirmed cases of PCOS based on Rotterdam Criteria which requires the presence of any two of the following:

- Oligo/anovulation

- Clinical or biochemical signs of hyperandrogenism

- Polycystic Ovaries on Ultrasound

- Subjects willing to be a part of the study.

\section{EXCLUSION CRITERIA:}

- Subjects beyond the required age group.

- Individuals with congenital adrenal hyperplasia, androgen secreting tumors, Cushing syndrome, thyroid dysfunction and hyperprolactinemia as mentioned in the Rotterdam criteria of PCOS diagnosis.

\section{Research Design}

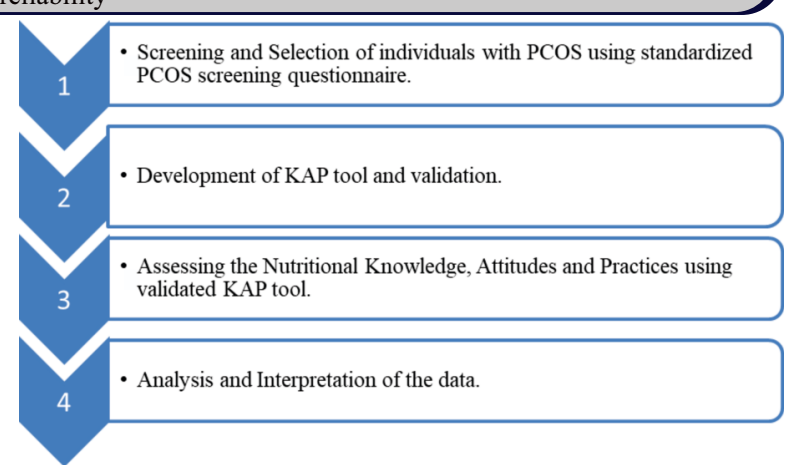

\section{EVALUATION TOOLS}

a) SCREENING QUESTIONNAIRE

A pre-developed screening questionnaire was used to screen and identify women with PCOS. The questions were based on Awareness, Diagnosis, symptoms of PCOS and presence of any psychological conditions such as stress, depression, body image issues etc.

b) KAP questionnaire- KAP questionnaire was constructed and validated with the aim of assessing knowledge, attitudes and practice of the subjects.

Knowledge, attitude and practice play main roles in the KnowledgeAttitude-Practice (KAP) model, which proposes that accumulated knowledge in a health aspect initiates changes in attitude, and results in gradual behavior change.[4]

Development - The aim was to develop and examine the validity and reliability of the KAP questionnaire towards the syndrome among PCOS women aged 15-25 years. Various literatures were reviewed using journal databases, existing reports, books, opinion from the experts and inputs from the diagnosed PCOS cases. The retrieved information was included in knowledge, attitude and practice domains.

Validation-Validity has been described as the agreement between a test score or measure and the quality it is believed to measure. [5]

Face validity- The retrieved information was included in knowledge, attitude and practice domains. Following this, a guided selfadministered questionnaire was developed which comprised 25 
Volume - $10 \mid$ Issue - 9 | September - 2020 | PRINT ISSN No. 2249 - 555X | DOI : 10.36106/ijar

knowledge items, 19 attitude items and 27 practice items. Items were generated with emphasis on features of PCOS.

Content validity- Content validity refers to the extent to which the items on a measure assess the same content .[6] Content Validity is based on the extent to which a measurement reflects the specific intended domain of content.[7]It refers to the conceptualization of the statements for developing the scale for the study. The developed KAP questionnaire was reviewed by a panel of 12 experts including registered dietician, academicians, gynecologist, psychologist and confirmed PCOS cases. The experts reviewed each item of the questionnaire based on content relevance, clarity, simplicity and ambiguity and rated each question on the following scale of 5[8]

- Not necessary

- Less than average

- Average

- Significant

- Most significant

The comments from content and face validation were considered and items were either edited, removed or remain unchanged with the help of factor analysis.

Factor analysis -. It assesses the degree to which the individual items on a scale truly cluster around one or more concepts. Items designed to measure the same concept should load on the same factor.

Reliability-reliability is the extent to which the instrument yields the same results on repeated measures. It is concerned with consistency, accuracy, precision, stability and homogeneity.

\section{Assessment of knowledge, attitude and practice}

In diagnosed and confirmed cases knowledge, attitudes and practices were assessed based on their awareness about the disease, symptoms, consequences, personal experience and concern towards the disease and their adopted lifestyle modifications.

This was followed by Statistical interpretation of the data.

\section{Ethical considerations}

The protocol was approved by the institutional human ethical committee-Nutri-Explore ethics committee (NEEC BU 012).An approved consent was also obtained from the study participants.

\section{RESULTS}

\section{Screening questionnaire}

\section{General information of the subjects}

It was observed that the $67 \%$ of the subjects were in the age group of 15 -18 years, $30 \%$ and $3 \%$ of the subjects were between $19-22$ and $27-30$ years of age respectively.

$99 \%$ of the subjects were single whereas $1 \%$ of the population was married.

\section{Table 1. Menstruation related symptoms}

Average age of menarche in the study population was found to be 12.7 years.

\begin{tabular}{|c|c|c|c|}
\hline \multirow{5}{*}{$\begin{array}{l}\text { Occurrence of } \\
\text { regular } \\
\text { menstruation }\end{array}$} & & Number & Percentage \\
\hline & Yes & 384 & 74 \\
\hline & No & 56 & 11 \\
\hline & \begin{tabular}{|l|} 
Sometimes \\
\end{tabular} & 81 & 15 \\
\hline & Total & 521 & 100 \\
\hline \multirow{6}{*}{$\begin{array}{l}\text { Frequency of } \\
\text { occurrence of } \\
\text { menstrual } \\
\text { cycle }\end{array}$} & & Number & Percentage \\
\hline & Less than 25 days & 58 & 11 \\
\hline & Every $25^{\text {th }}$ day & 200 & 38 \\
\hline & \begin{tabular}{|l|} 
More than 30 days \\
\end{tabular} & 110 & 21 \\
\hline & Variable days & 153 & 30 \\
\hline & Total & 521 & 100 \\
\hline \multirow{6}{*}{\begin{tabular}{|l} 
Time of \\
noticing \\
irregular \\
menstrual \\
cycle
\end{tabular}} & & Number & Percentage \\
\hline & \begin{tabular}{|l|} 
No irregularity \\
\end{tabular} & 189 & 36 \\
\hline & $\begin{array}{l}\text { A year after attaining } \\
\text { puberty }\end{array}$ & 178 & 34 \\
\hline & \begin{tabular}{|l|} 
Two years later \\
\end{tabular} & 40 & 8 \\
\hline & $\begin{array}{l}\text { After more than two } \\
\text { years }\end{array}$ & 114 & 22 \\
\hline & Total & 521 & 100 \\
\hline \begin{tabular}{|l|} 
Observation \\
during \\
menstruation
\end{tabular} & & Number & Percentage \\
\hline
\end{tabular}

\begin{tabular}{|l|l|l|l|}
\hline & Heavy bleeding & 82 & 16 \\
\hline & Moderate bleeding & 373 & 72 \\
\hline Spotting & 11 & 2 \\
\hline & Blood clots & 55 & 10 \\
\hline & Total & 521 & 100 \\
\hline
\end{tabular}

It can be observed from the above table that $26 \%$ of these subjects showed irregularity in the menstruation. For $11 \%$ of the subjects, the duration of menstrual cycle was found to be less than 25 days, $34 \%$ of the subjects noticed irregularity in menstruation a year after attaining puberty and $16 \%$ of the subjects had heavy bleeding during menstruation.

Table 2 Diagnosis and Clinical signs of PCOS among the subjects.

\begin{tabular}{|c|c|c|c|}
\hline Subjects diagnosed with & & Number & Percentage \\
\cline { 2 - 4 } & Yes & 56 & 11 \\
\cline { 2 - 4 } & No & 465 & 89 \\
\cline { 2 - 4 } & Total & 521 & 100 \\
\hline \multirow{4}{*}{$\begin{array}{c}\text { Specific test done by the } \\
\text { subjects for the diagnosis } \\
\text { of PCOS }\end{array}$} & Yes & Number & Percentage \\
\cline { 2 - 4 } & No & 40 & 12 \\
\cline { 2 - 4 } & Total & 521 & 88 \\
\hline $\begin{array}{c}\text { Excess of hair growth on } \\
\text { face }\end{array}$ & Yes & 57 & 100 \\
\cline { 2 - 4 } & No & 464 & 89 \\
\cline { 2 - 4 } & Total & 521 & 100 \\
\hline \multirow{4}{*}{$\begin{array}{c}\text { Presence of coarse hair } \\
\text { growth at 3 or more sites }\end{array}$} & Yes & Number & Percentage \\
\cline { 2 - 4 } & No & 46 & 17 \\
\cline { 2 - 4 } & Total & 521 & 83 \\
\hline
\end{tabular}

The above table shows that among the study population $11 \%$ of the subjects were diagnosed with PCOS. Though from the same study it was found $26 \%$ of the study population was at risk of PCOS.

It was also observed that $12 \%$ of the subjects got specific test done for the diagnosis of PCOS and $11 \%$ of the subjects were found to have excess hair growth on the face whereas $17 \%$ of the subjects had coarse hair growth at 3 or more site.

Table 3. Correlation between PCOS and menstruation Irregularity

\begin{tabular}{|c|c|c|c|c|c|}
\hline $\begin{array}{c}\text { Undergone } \\
\text { tests to } \\
\text { confirm } \\
\text { PCOS }\end{array}$ & \multicolumn{2}{|c|}{ Notice of irregular Menstrual cycle } & Significance \\
\cline { 2 - 5 } & $\begin{array}{c}\text { No } \\
\text { irregularity }\end{array}$ & $\begin{array}{c}\text { A year } \\
\text { after } \\
\text { attaining } \\
\text { puberty }\end{array}$ & $\begin{array}{c}\text { Two years } \\
\text { later }\end{array}$ & $\begin{array}{c}\text { After } \\
\text { more than } \\
\text { two years }\end{array}$ & \\
square test \\
\hline Yes(56) & 1 & 24 & 10 & 21 & $18.2345^{* *}$ \\
\hline No(465) & 188 & 154 & 30 & 93 & \\
\hline
\end{tabular}

\section{** Significant at $1 \%$ level}

The above table suggests that confirmation of PCOS had significantly higher association with irregularity of menstrual cycle with the chi square value being 18.2345 .

Table 4 Correlation between PCOS and clinical sign

\begin{tabular}{|l|l|l|}
\hline Undergone tests & Excess growth of hair on face & Significance of \\
\hline
\end{tabular} \begin{tabular}{|r|c|c|}
\hline to confirm PCOS & Yes & No \\
\cline { 2 - 3 } Chi square test
\end{tabular}

\begin{tabular}{|c|c|c|c|} 
to confirm PCOS & Yes & No & Chi square test \\
\hline Yes & 21 & 35 & $21.1607^{* *}$ \\
\hline No & 37 & 428 & \\
\hline \multicolumn{4}{|c|}{ ** Significant at 1\% level } \\
\hline $\begin{array}{c}\text { Undergone tests } \\
\text { to confirm PCOS }\end{array}$ & $\begin{array}{c}\text { Coarse hair growth } \\
\text { at 3 or more sites }\end{array}$ & \multicolumn{2}{|c|}{$\begin{array}{c}\text { Significance of Chi } \\
\text { square test }\end{array}$} \\
\hline & Yes & No & \\
\hline Yes & $\mathbf{2 0}$ & $\mathbf{3 6}$ & $16.3090^{* *}$ \\
\hline No & $\mathbf{6 7}$ & $\mathbf{3 9 8}$ & \\
\hline \multicolumn{4}{|c}{ * Significant at 1\% level } \\
\end{tabular}

It can be concluded from table 4 that there was a significant association seen between confirmation of PCOS and coarse hair growth at 3 or more sites and the chi square value was found to be 16.3090 .

\section{KAPQuestionnaire}

Content validity

For the content validation, the KAP questionnaire was given to the 
expert panel. Several suggestions and feedbacks were received related to the framing of questions and every item in the questionnaire was rated as adequately relevant, clear, simple and non- ambiguous. With this, the tool was made adequate for the present study.

\section{Construct validity}

Based on the comments provided by the expert panel, factor analysis was done to assess construct validity which helped to check the importance of each questions. It was found that knowledge section of the instrument had 25 questions initially. Among 25 questions, factor analysis showed 7 components with cumulative percentage variance of $94 \%$ which were later plotted on scree plot to derive eigen values. These component matrix were then rotated with the Varimax with Kaiser Normalization method in which question no. 9 and 24 were discarded and rest 23 were selected for the further study.

Attitude section had 19 questions initially among which factor analysis showed 6 components with cumulative percentage variance of $89 \%$ which were later plotted on scree plot to derive eigen values. These component matrix were then rotated with the Varimax with Kaiser Normalization method in which question no. 12, 14, 15 and 17 were discarded and rest 15 were selected

Practice section had 25 questions initially among which factor analysis showed 7 components with cumulative percentage variance of $94.6 \%$ which were later plotted on scree plot to derive eigen values. These component matrix were then rotated with the Varimax with Kaiser Normalization method in which question no. 11, 21 and 24 were discarded and rest 23 were selected for the further study.

\section{Reliability}

Reliability analysis was done to assess the reliability of the instrument. For this, split of reliability was worked out to find the correlation

\section{Table 5.Reliablity analysis}

\begin{tabular}{|c|c|c|c|}
\hline & Reliability & Cronbach's Alpha I & Cronbach's Alpha II \\
\hline Knowledge & $0.83(83 \%)$ & .712 & .301 \\
\hline Attitude & $0.63(63 \%)$ & .481 & .272 \\
\hline Practice & $0.48(48 \%)$ & .630 & .810 \\
\hline
\end{tabular}

The Knowledge tool had an association (Correlation) of $83 \%$. Higher
the value of reliability coefficient, higher will be the correlation i.e. the instrument was found to be more reliable for further use.

The Cronbach's Alpha for part I and part II gives the strength when the items are divided in two parts. (Split half) The significance of reliability coefficient is not tested.

\section{Assessment of knowledge, attitudes and practices}

The analysis of validated KAP questionnaire showed that knowledge scores among the subjects $(\mathrm{n}=40)$ was found to be $80.5 \pm 15.02$, attitude scores was $43.95 \pm 6.61$ and practice score was found to be $60.10 \pm 6.86$

Table 6.Correlation between Knowledge, Attitude and Practice among subjects

\begin{tabular}{|c|c|c|c|}
\hline & Knowledge & Attitude & Practice \\
\hline Knowledge & 1.0000 & & \\
\hline Attitude & $0.7356^{* *}$ & 1.0000 & \\
\hline Practice & $0.5249^{* *}$ & $0.5693^{* *}$ & 1.0000 \\
\hline
\end{tabular}

The above table shows that there was a significant correlation between Knowledge and Attitude (0.7356). A significant correlation also exists between Knowledge and Practice (0.5249) and Attitude and Practice (0.5693) among the subjects.

\section{DISCUSSION}

The conducted study showed that PCOS has a great association with menstrual irregularity and facial hair growth.

In one of the study conducted it was observed that the prevalence of Polycystic Ovaries increased significantly with the irregularity of the menstrual cycle pattern. [9]

Similar findings were reported where it was observed that the excess amount of androgens production in PCOS women prevents ovulation,may cause infertility, acne and abnormal hair growth, such as excess facial hair or male pattern baldness.[10]
In another study conducted in New Delhi to study the clinical manifestations in PCOS women it was found that the prevalence of menstrual irregularities, clinical hyperandrogenism, endometrial hyperplasia $(\mathrm{EH})$, and type 2 diabetes mellitus was significantly higher in the PCOS women.[11]

There is an escalation in the prevalence of PCOS due to the nutritional transitions of developing countries towards obesogenic lifestyle. The rising incidence coupled with the etiological complexity of PCOS calls for the effective management of this condition to improve the quality of life.

The Developed KAP Questionnaire helped in acquiring the information regarding Knowledge, Attitude and Practices of the selected subjects pertaining to Nutrition and PCOS .It was clearly evident that the subjects had low attitude and their practices were not commensurate with the knowledge they had about PCOS and Nutrition. Contrasting results were observed in one of the study conducted by Patel et al ,2018 in young central Indian Population, where among 400 participants, only $41 \%$ of the women were aware of the term PCOS and very few young women understood the earliest symptoms that should alarm them to consult a physician.

Another study observed that most of the subjects in the study had poor knowledge regarding polycystic ovarian syndrome. After the educational sessions there was enhancement of knowledge score on polycystic ovarian syndrome. [12]

Similar findings were obtained in one more study where nutrition education improved KAP scores significantly and Ninety-seven per cent of the participants rated the overall intervention and its delivery as 'very good to excellent', reporting that they would recommend this educational intervention to colleagues.[13]

\section{CONCLUSION}

The study is helpful in addressing the gaps in knowledge, attitudes and practices and encourage females to consult health professionals for effective management of PCOS . The study also paves the way for the development of nutrition education material and initiation of awareness generation programs for PCOS

Many studies have shown that Educational program conducted regarding PCOS, Diet and Lifestyle intervention have improved the knowledge, attitudes and practices among women with PCOS. The developed questionnaire can be used to identify the gaps among the target population and would further help in designing the various awareness and educational programs for PCOS population.

ACKNOWLEDGEMENT: The authors are thankful to the subjects for eliciting information and helping in the successful conduction of the study.

'The author(s) declare that they have no competing interests'

\section{Conflict of interest-NIL}

The manuscript has been read and approved by all the authors. We hereby transfer, assign, or otherwise convey all copyright ownership, including any and all rights incidental thereto, exclusively to the journal, in the event that such work is published by the journal.

\section{REFERENCES:}

1. The Rotterdam ESHRE/ASRM-sponsored PCOS consensus workshop group. Revised 2003 consensus on diagnostic criteria and long-term health risks related to polycystic ovary syndrome (PCOS). Hum Reprod 2004;19:41-7.

2. Nidhi, R., Padmalatha, V., Nagarathna, R., \& Amritanshu, R. (2012). Effect of holistic yoga program on anxiety symptoms in adolescent girls with polycystic ovarian syndrome: A randomized control trial. International journal of yoga, 5(2), 112

3. Kabel, A. M. (2016). Polycystic ovarian syndrome: insights into pathogenesis, diagnosis, prognosis, pharmacological and non-pharmacological treatment. J Pharma Reports, 1(103), 2 .

4. Hiew, C., Chin, Y., Chan, Y., \& Mohd, N. M. (2015). Development and Validation o Knowledge, Attitude and Practice on Healthy Lifestyle Questionnaire (KAP-HLQ) for Malaysian Adolescents. Journal of Nutrition and Health Sciences, 2(4), 1-11

5. Kaplan, R. M., \& Saccuzzo, D. P. (2017). Psychological testing: Principles, applications, and issues. Nelson Education.

6. Rubio, D. M., Berg-Weger, M., Tebb, S. S., Lee, E. S., \& Rauch, S. (2003). Objectifying content validity: Conducting a content validity study in social work research. Social content validity: Conducting
work research, $27(2), 94-104$.

7. Carmines, E. G., \& Zeller, R. A. (1979). Reliability and validity assessment (Vol. 17) Sage publications.

8. Koo, H. C., Poh, B. K., \& Ruzita, A. T. (2016). Development, validity and reliability of a questionnaire on knowledge, attitude and practice (KAP) towards whole grain among primary school children in Kuala Lumpur, Malaysia. International Food Research Journal, 23(2). 
9. Van Hooff, M. H., Voorhorst, F. J., Kaptein, M. B., Hirasing, R. A., Koppenaal, C., \& Schoemaker, J. (2000). Polycystic ovaries in adolescents and the relationship with menstrual cycle patterns, luteinizing hormone, androgens, and insulin. Fertility and sterility, 74(1), 49-58.

10. Jahangir, S. (2017). A Study On Knowledge \& Awareness Of Polycystic Ovarian Syndrome Among Female Non Medical Undergraduate Students (Doctoral dissertation, East West University).

11. Majumdar, A., \& Singh, T. A. (2009). Comparison of clinical features and health manifestations in lean vs. obese Indian women with polycystic ovarian syndrome. Journal of human reproductive sciences, 2(1), 12 .

12. Mohamed, H. A. A. (2016). Effect of educational program on the level of knowledge regarding polycystic ovarian syndrome among adolescent girls. Journal of Nursing Education and Practice, 6(10), 80,

13. Ray, S., Udumyan, R., Rajput-Ray, M., Thompson, B., Lodge, K. M., Douglas, P., .. \& Gillam, S . (2012). Evaluation of a novel nutrition education intervention for medical students from across England. BMJ open, 2(1), e000417. 